\title{
sciendo
}

Current Issues in Pharmacy and Medical Sciences

Formerly ANNALES UNIVERSITATIS MARIAE CURIE-SKLODOWSKA, SECTIO DDD, PHARMACIA

\section{Overview of phenotypic methods used for differentiation of Staphylococcus aureus}

\author{
Martyna Kasela*, Anna Malm
}

Department of Pharmaceutical Microbiology with Laboratory for Microbiological Diagnostics, Medical University of Lublin, Chodzki 1, 20-093, Lublin, Poland

\section{ARTICLE INFO \\ Received 06 February 2018 \\ Accepted 29 March 2018}

\section{Keywords:}

Staphylococcus aureus, phenotypic methods, differentiation, typing.

\begin{abstract}
Choosing the appropriate method for differentiation of Staphylococcus aureus strains is important for effective diagnostics and epidemiological investigations. Despite the fact that the results of phenotypic methods are strongly dependent on environmental conditions, they can still be useful in the investigation of epidemic strains of S. aureus. In this article, the potential application of commonly used phenotypic methods in epidemiological studies of $S$. aureus was analysed. Advantages and disadvantages of methods such as biotyping, serotyping, phage typing, AST (Antimicrobial Susceptibility Testing), SDS-PAGE (Sodium Dodecyl Sulphate Polyacryl Gel Electrophoresis), MLEE (Multilocus Enzyme Electrophoresis) and MALDI-TOF MS (Matrix-Assisted Laser Desorption/Ionization Time-Of-Flight Mass Spectroscopy) were also discussed. Finally, phenotypic techniques were compared in terms of their discriminatory potential, typeability of isolates, time of analysis, reproducibility, ease of performance and ease of results interpretation.
\end{abstract}

\section{INTRODUCTION}

Staphylococcus aureus is one of the most widespread bacteria in the environment. On the one hand, it can belong to the physiological human microbiota, on the other, it is etiological factor in many kinds of diseases, ranging from mild to potentially fatal [1]. In 1961, the first strains of MRSA (methicillin-resistant $S$. aureus) appeared in hospitals. Since then, $S$. aureus strains, especially that multi-resistant, have spread around the world, both in hospital environments and in the community, causing a global problem to public health [2]. The control of dissemination and the understanding of the clonal structure of multidrug resistant strains of $S$. aureus are some of the most challenging issues of modern epidemiology.

Nowadays, typing of $S$. aureus is based mainly on molecular techniques. Although genotyping techniques are wellknown for their high discriminatory power and reproducibility, not all laboratories have access to the equipment which is necessary to conduct the studies. Before the molecular biology era, phenotypic methods were used in epidemiological studies of $S$. aureus. Phenotypic methods measure the visible characteristics of tested microorganisms, and the main disadvantage of these methods is that expression

\footnotetext{
* Corresponding author

e-mail: kasela.martyna@gmail.com
}

of bacterial genetic material may occur spontaneously or as a response to stimuli from the environment. The effect is that genetically indistinguishable isolates can have different phenotypes and the unrelated strains may exhibit the same phenotype properties. Moreover, large fractions of strains are often untypable [3]. Despite this disadvantages, phenotypic methods can be still regarded as irreplaceable tool in the early stages of epidemiological studies of human pathogens, including $S$. aureus [4].

\section{BIOTYPING}

Biotyping is one of the first methods developed for differentiating bacterial strains. In its simplest version, biotyping of $S$. aureus is based on the results of three reactions: production of staphylokinase and $\beta$-hemolysin enzymes, coagulation of bovine plasma and observation of growth properties on an agar containing crystal violet $[5,6]$. This method allows for differentiation of bacterial strains from various animal species and thus assigns bacterial isolates to biotypes and ecological variants [7]. Since the method was developed, the panel of studied biochemical characteristics of tested isolates has been extended [6]. Nowadays, biochemical tests are diagnostic tools used in routine species identification based on the ability of microorganisms to synthesize 
enzymes and degrade and assimilate different compounds, for example, carbohydrates [8]. Biotyping, similarly to other phenotypic methods, has a very low discrimination power in comparison to genotypic methods $[9,10]$. Phenotypic traits of the same isolate included in biotyping may vary in different environmental conditions [10]. Because of the low cost of the method and its simplicity, it is still performed in diagnostic laboratories and considered a valuable auxiliary tool in the epidemiological studies of $S$. aureus. Moreover, there are many commercially available tests for determining biochemical profiles, for instance, the automated VITEK systems and manual API tests, usually used for diagnostic purposes [7].

\section{SEROTYPING}

Serotyping is based on differences in the structure of antigenic determinants (such as lipopolysaccharides and membrane proteins) located on the surface of bacterial cells [11]. Currently, 11 capsular types of $S$. aureus are distinguished, whereas $85-90 \%$ of all tested MRSA strains belong to type 5 or $8[6,12]$. This low degree of allelic variation of genes encoding particular types of capsular polysaccharides was also confirmed in molecular analysis conducted by Sutter et al. [13], where genetic material of all tested CA-MRSA (community-acquired MRSA) isolates contained cap5 and cap 8 genes. Since the production of capsular polysaccharides is highly dependent on environmental factors, molecular methods are currently used to determine the capsular type of isolates [14].

Another version of serotyping (used mainly in Japan) is coagulase typing. In this, the domination of the two aforementioned serotypes of this enzyme among the tested isolates has also been observed. Due to the very low discriminating power, serotyping is not used in the epidemiological studies of $S$. aureus [15].

\section{PHAGE TYPING}

Phage (bacteriophage) typing was developed in the 1940s. This method has been standardized very early. Indeed, IUMS (International Union of Microbiological Societes) began working on the unification of the phage typing principles as of $1953[11,12,15]$. Bacteriophages are characterized by specificity - they can interact only with certain bacterial strains. Bacteria, in turn, have a specific phage pattern, what means that they can only be lysed by certain kind of phages. Four groups of phages (I-IV) and one mixed group were identified in the phagotyping of human pathogenic S. aureus strains [6]. Since then, a set consisting of 23 phages has been commonly used $[6,12,16]$. Phages are inoculated on agar surface on which the tested $S$. aureus isolate is located. Areas where lysis of bacterial cells has occurred are called 'phage plaques'. Such a reaction may be classified as weak or strong. If less than 50 plaques on a plate are observed, the reaction is treated as weak [12,17]. In studies aimed at determining the phylogenetic relationship of $S$. aureus strains, only the results obtained in strong reactions are taken into account. In the absence of such reaction, a hundred fold concentration of phages is used.
Although phage typing is one of the most useful phenotypic methods in epidemiological studies, it has numerous disadvantages. Its discriminating power can be reduced by the fact that some of the tested bacterial strains are untypable. In case of phage typing of MRSA strains, the percentage of untypable isolates reaches at least $20-30 \%$. Moreover, the phage pattern of some strains can undergo significant changes over time. Such a poor reproducibility of the already labor-intensive and time-consuming method limits the possibility of obtaining information on the relationship of the tested strains. It is also necessary to follow the instructions in the protocols very carefully in order to maintain the desired population of phages and achieve reliable and internationally comparable results [11]. Furthermore, insufficient differentiation potential has contributed to the decline in the popularity of the once often used method of staphylococcal typing $[6,12]$

The advantage of the method is that individual types of phages and individual phage groups can be linked to traits of high importance in the context of nosocomial infections, such as drug resistance [18]. Moreover, many researchers have found a connection between 81 phage type and the sensitivity of these strains to all antibiotics except for penicillin [19]. Phagotyping can, hence, be used in the initial epidemiological studies of MRSA strains, for example, in the identification of previously known epidemic strains in the occurrence of an outbreak [11,20]. Until the early 1990s and the introduction of the first method of molecular typing of microorganisms - PFGE (Pulsed-Field Gel Electrophoresis), phagotyping was the main method used in typing of clinical $S$. aureus strains [17]. Currently, this method is less frequently used, but it can provide valuable information about the prevalence of epidemic $S$. aureus strains [21].

\section{ANTIMICROBIAL SUSCEPTIBILITY TESTING (AST)}

The typing of microorganisms based on their antibiotic susceptibility profile is a commonly used method which is widely recognized due to the simplicity of its implementation, low costs and the fact that it is well standardized $[6,12,22,23]$. Standardization allows for the comparison of results between laboratories around the world that work according to the standards set by NCCLS (National Committee for Clinical Laboratory Standards) [6]. The interpretation of antibiograms is relatively easy because many organizations, such as CLSI (Clinical Laboratory Standards Institute) or EUCAST (European Committee on Antimicrobial Susceptibility Testing) are still working on the improvement of the AST protocols [24]. The most popular, routinely used version of the method for the determination of antimicrobial susceptibility is the Kirby-Bauer method $[6,23]$. Theoretically, determining the resistance or sensitivity to an antimicrobial drug allows to classify the isolate to a particular clone. However, it is well-known that the expression of antimicrobial resistance is strongly dependent on environmental conditions. Therefore, the same antibiograms can be obtained by examining strains that are not related to each other, such as strains belonging to the same clone which may have a different susceptibility profile $[6,11,12]$. Despite the satisfactory speed of obtaining results, however, 
they are not a sufficient basis for MRSA typing [11]. This is because antibiotic resistance patterns are highly dependent on selective antibiotic pressure, as well as the presence of plasmids carrying antibiotic resistance genes or other mobile genetic elements like transposons $[6,11,12,22,24]$.

Until recently, antibiogram was considered a valuable tool for differentiating CA-MRSA from HA-MRSA (hospital-associated MRSA). Unfortunately, because of the transmission of CA-MRSA strains to the hospital environment and the increase in their resistance to antibiotics, distinguishing CA-MRSA from HA-MRSA is becoming more problematic [24].

Antimicrobial susceptibility testing is still a valuable tool in preliminary studies of multi-drug resistant strains of $S$. aureus. For example, sensitivity to gentamycin is an important epidemiological marker in the identification of certain MRSA clones, and clindamycin sensitivity is characteristic for CA-MRSA strains [11]. In the current epidemiological studies of multi-drug resistant $S$. aureus strains, it is a method that can be very helpful in initial characterization of the tested isolates [12,22].

\section{PROTEIN PROFILING BY SODIUM DODECYL SULPHATE POLYACRYL GEL ELECTROPHORESIS (SDS-PAGE)}

Protein electrophoresis allows an analysis of the profile of cellular proteins, and enables a comparison of individual bacterial strains. The principle of all variants of this method is basically the same. After the lysis of the bacterial cell, the electrophoretic separation of the proteins is performed [6]. If all proteins present in the bacterial cell are subjected to the separation, this method is called SDS-PAGE [12]. In this method, the proteins are extracted from the cell, separated with SDS and stained by Coomassie, silver, zinc or fluorescent dye [11]. As a result of this separation, a pattern of approximately 50 bands is obtained.

This method is, unfortunately, practically completely unusable for epidemiological analysis of $S$. aureus, even if the differences between completely unrelated strains of this microorganism are not minor $[6,11,12]$. It is also not possible to link the results obtained with this method with other typing methods - an activity which could enrich the results obtained in the studies. In addition, SDS-PAGE is very sensitive to fluctuations of environmental factors, which make it rarely used in epidemiological studies [12].

Currently, there are many improved and modified forms of techniques based on protein electrophoresis. A very well-known example is immunoblotting, which involves the Western-Blot reaction using labelled staphylococcal antibodies with the antigens of the tested strain $[6,11,12]$. The source of those antibodies can be the plasma of an organism that previously had contact with $S$. aureus [12]. Due to the smaller number of obtained bands, immunoblotting is more useful than SDS-PAGE because its results are easier to interpret. However, its discriminating power is still insufficient to be considered useful in the study of epidemic strains [6].

\section{ENZYME PROFILING BY MULTILOCUS ENZYME ELECTROPHORESIS (MLEE)}

Another variant of protein electrophoresis is the MLEE, which analyses the enzymes of bacterial cells. On the basis of the differences and similarities in the electrophoretic profile of isolates, they are classified into individual electrophoretic types. MLEE uses the phenomenon of cellular enzymes polymorphism [6,12,25]. An important element that can significantly increase the discriminating power of this method is the appropriate selection of a wide panel of studied enzymes. The enzymes taken into account in this reaction cannot be monomorphic, because of their low degree of allelic variation. Due to the relatively high reproducibility, it is one of the most acceptable methods for differentiating bacterial isolates based on their phenotypic traits $[6,25]$. The degree of enzyme migration in the gel depends on their amino acid composition. Indeed, it has been shown that over $80 \%$ of substitutions can be detected by appropriate selection of reaction conditions.

Such an enzymatic profile may theoretically be a substitute for molecular methods because it allows to indirectly reflect the variants of genes encoding the tested enzymes [12]. It is worth noting that in the case of MRSA, all strains are typable, although the differentiating potential depends strictly on the number and type of the selected enzymes [11]. The basic panel contains from 12 to 20 enzymes [12]. Metabolic enzymes are not directly subjected to selective pressure or evolutionary convergence and their individual loci are usually independent and coded by the housekeeping genes. Because of that, such analysis provides additional phylogenetic information [26]. The application of the MLEE method in $S$. aureus population studies has revealed the clonal nature of the population of this pathogen [25].

\section{PROTEIN PROFILING BY MATRIX-ASSISTED LASER DESORPTION/IONIZATION TIME-OF-FLIGHT MASS SPECTROMETRY (MALDI-TOF MS)}

Identification of microorganisms by the means of mass spectrometry is a method widely used in microbiological diagnostics. MALDI-TOF MS can identify animal pathogens, as well as microorganisms, from clinical sources and from the environment [27]. It is based on examining the protein profile of the isolate, and it creates a 'fingerprint' unique for a given species. Furthermore, it is simple to execute and is automated [27-30]. Moreover, its use significantly shortens the time of identification of the tested microorganism - after bacteria isolation and preparation of sample, only a few minutes are needed for examination $[27,29]$. It also does not need large amounts of diagnostic material for analysis. The minimum number of bacterial cells necessary for correct identification of a species is about $10^{5}$ [27]. Additionally, it was noticed that the concentration of bacterial cells in the sample significantly influences the efficiency of the method [28].

Compared to routinely used biochemical methods for identification of microorganisms, methods based on mass spectrometry also allow the identification of rare microorganisms. 
In addition, MALDI-TOF MS databases are more developed than those used in biochemical techniques [27]. In studies conducted by Szabados et al. [31], this method identified 361 species correctly from 363 MSSA strains, whereas of MRSA, it was $100 \%$ correct identification. By way of this method, it is also possible to determine the degree of relationship between the bacterial strains belonging to the same species. Moreover, it is possible to analyse many samples in a short time, and, above all, it does not require preliminary identification, as is in the case of biochemical tests, where it is necessary to classify the investigated organism first. Despite the fact that proteomic technology is commonly used for species identification, currently, researchers are trying to interpret differences in the spectra of proteins and assign them to genetic information obtained by using molecular methods. However, in the search for such links, several factors that can significantly influence the results of the study should be taken into account. For example, two spectra may differ in such parameters as the signal strength or its total absence. These discrepancies in signals do not need to correlate with the differences in bacterial genome because they may be the result of various microbial incubation conditions. The disappearance of the signal at a particular site may mean the lack of expression of a certain gene encoding given protein, a mutation in the genetic material or the presence of a stop codon. Researchers constantly try to identify polymorphic peptides visible in the resulting spectrum and establish the correlation between obtained results and differences in bacterial genome. Most of the studied signals are created by ribosomal proteins and toxins, especially those encoded by less conservative genes than the housekeeping genes [32].

Studies on adapting this method to the detection of virulence factors and resistance markers are in progress. These studies demonstrated the utility of MALDI-TOF MS in determining the ability of $S$. aureus strain to produce a delta toxin (spectral peaks corresponding to this protein have been identified) [29]. As of the moment, the main reason why MALDI-TOF MS is not used for routine epidemiological studies is lack of guidelines for its validation, application and interpretation of obtained data in the context of bacterial typing. Adapting MALDI-TOF MS for epidemiological typing is, hence, still in progress. Researchers have found that discriminatory power of MALDI-TOF MS and spa typing are comparable. What is more, basing on present studies results, MALDI-TOF MS has a potential to become a quick screening method for detecting epidemic strains of S. aureus, such as USA300 [33]. Currently, there are no official guidelines for the standardization of this method, especially for the process of preparing samples for the study, yet, standardization facilitates the comparison of results between laboratories [27].

\section{CONCLUSION}

Several phenotypic methods were used for differentiation of $S$. aureus strains (Table 1). Nowadays, only some are useful for epidemiological purposes, among these, bacteriophage typing or protein electrophoresis techniques. However, their application is limited due to long time of analysis, insufficient percentage of typable strains and the relatively poor differentiation potential of investigated $S$. aureus isolates. On the other hand, methods such as biotyping, AST and MALDI-TOF MS are being used successfully for diagnostic purposes.

Table 1. Comparison of phenotypic methods used for differentiation of Staphylococcus aureus

\begin{tabular}{|l|c|c|c|c|c|c|c|}
\hline \multicolumn{1}{|c|}{ Method } & $\begin{array}{c}\text { Typeability } \\
\text { of isolates }\end{array}$ & $\begin{array}{c}\text { Ease of } \\
\text { performance }\end{array}$ & $\begin{array}{c}\text { Ease of } \\
\text { interpretation }\end{array}$ & Reproducibility & $\begin{array}{c}\text { Time of } \\
\text { analysis } \\
\text { [days] }\end{array}$ & $\begin{array}{c}\text { Differentiating } \\
\text { power }\end{array}$ & $\begin{array}{c}\text { Practical } \\
\text { application }\end{array}$ \\
\hline Biotyping & $100 \%$ & easy & easy & good & 1 & low & $\begin{array}{c}\text { species } \\
\text { identification }\end{array}$ \\
\hline Serotyping & $100 \%$ & easy & easy & very good & 1 & very low & $\begin{array}{c}\text { determining } \\
\text { capsular type } \\
\text { of isolate }\end{array}$ \\
\hline Phage typing & $70-90 \%$ & medium & medium & good & 1 & medium & $\begin{array}{c}\text { differentiation } \\
\text { and typing } \\
\text { of epidemic } \\
\text { strains }\end{array}$ \\
\hline AST & $100 \%$ & easy & easy & very good & 1 & low & $\begin{array}{c}\text { determining } \\
\text { of antibiotic } \\
\text { resistance } \\
\text { profile }\end{array}$ \\
\hline SDS-PAGE & $90-100 \%$ & easy & easy & good & 1 & low & $\begin{array}{c}\text { comparison } \\
\text { of isolates }\end{array}$ \\
\hline MLEE & $90-100 \%$ & easy & medium & good & $1-2$ & medium & $\begin{array}{c}\text { differentiation } \\
\text { of strains }\end{array}$ \\
\hline MALDI-TOF MS & $100 \%$ & medium & medium & very good & 1 & high & $\begin{array}{c}\text { species } \\
\text { identification }\end{array}$ \\
\hline
\end{tabular}

Phenotypic methods will never match genotypic methods in their discriminatory power, reproducibility, typability and time of analysis. However, it should be remembered that the former are less expensive, often easier to perform, and do not require specialized and expensive equipment. Most of these techniques are, however, treated as an auxiliary methods for genotyping systems as they provide valuable information about tested isolates, while some are being successfully adapted for epidemiological typing.

\section{REFERENCES}

1. Pomorska-Wesolowska M, Rozanska A., Natkaniec J, Gryglewska B, Szczypta A, Dzikowska M. Longevity and gender as the risk factors of methicillin-resistant Staphylococcus aureus infections in southern Poland. BMC Geriatr. 2017;17(1):51-8.

2. Denis O. Route of transmission of Staphylococcus aureus. Lancet Infect Dis. 2017;7(2):124-5.

3. Rao S. Epidemiological typing methods [Internet]. 2016 [cited 14 Jan 2018]. Available from: ttp://www.microrao.com/micronotes/ typing.pdf.

4. Stojowska K. Elaboration on new methods for genetic typing of bacteria based on ligation of oligonucleotide adapters to restriction fragments of genomic DNA and PCR techniques, application and evaluation of their usefulness in epidemiological studies [In Polish] Available from: http://pbc.gda.pl/Content/24012 [Accessed 14 Jan 2018].

5. Devriese LA. A simplified system for biotyping Staphylococcus aureus strains isolated from different animal species. J Appl Microbiol. 1984;56(2):215-20.

6. Miedzobrodzki J, Malachowa N, Markiewski T, Bialecka A, Kasprowicz A. Differentiation of Staphylococcus aureus isolates based on phenotypical characters [In Polish]. Postep Hig Med Dosw. 2008;62:322-7. 
7. Brzozowski M, Kwiatkowski P, Kosik-Bogacka D, Jursa-Kulesza J. The application of genotyping and phenotyping techniques for epidemiological analysis of microorganisms [In Polish]. Post Mikrobiol. 2017;56(3):353-66.

8. Samaranayake L. Essential Microbiology for Dentistry. Elsevier Health Sciences. 2011:p.50-1.

9. Ostojic M, Hukic M. Genotypic and phenotypic characteristics of methicillin-resistant Staphylococcus aureus (MRSA) strains, isolated on three different geography locations. Bosn J Basic Med Sci. 2015;15(3):48-56.

10. Bruisten SM, Schouls L. Molecular typing and clustering analysis as a tool for epidemiology of infectious diseases. In: Kramer A, Kretzschmar M, Krickeberg K, editors. Modern infectious disease epidemiology. New York: Springer;2009:117-41.

11. Mehndiratta PL, Bhalla P. Typing of methicillin resistant Staphylococcus aureus: a technical review. Indian J Med Microbiol. 2012;30(1):16-23.

12. Weller TMA. Methicillin-resistant Staphylococcus aureus typing methods: which should be the international standard? J Hosp Infect. 2000;44(3):160-72.

13. Sutter DE, Summers AM, Keys CE, Taylor KL, Frasch CE, Braun LE, et al. Capsular serotype of Staphylococcus aureus in the era of community-acquired MRSA. FEMS Immunol Med Microbiol. 2011;63(1):16-24.

14. O'Riordan K, Lee JC. Staphylococcus aureus capsular polysaccharides. Clin Microbiol Rev. 2004;7(1):218-34.

15. Marples RR, Rosdahl VT. International quality control of phage typing of Staphylococcus aureus. J Med Microbiol. 1997;46(6):511-6.

16. Lakshmi GJ. Mechanism of resistance, phenotyping and genotyping of methicillin resistant Staphylococcus aureus: A Review. Int J Curr Microbiol App Sci. 2015;4(4):810-8.

17. Stark L. Staphylococcus aureus: aspects of pathogenesis and molecular epidemiology. PhD Thesis. Linköping University Electronic Press, 2013.

18. Piechowicz L, Galinski J, Dajnowska-Stanczewa A, Garbacz K. Phage types of Staphylococcus aureus isolated in Poland in 1999-2004 [In Polish]. Med Dosw Mikrobiol. 2005;57(2):105-11.

19. Mehndiratta PL, Gur R, Saini S, Bhalla P. Staphylococcus aureus phage types and their correlation to antibiotic resistance. Indian J Pathol Microbiol. 2010;53(4):738-41.

20. Kareiviene V, Pavilonis A, Sinkute G, Liegiute S, Vizuje G. Staphylococcus aureus resistance to antibiotics and spread of phage types. Medicina. 2006;42(4):332-9.

21. Kali A, Stephen S, Sivaraman U, Kumar S, Joseph NM, Srirangaraj S, Easow JM. Bacteriophage types of methicillin-resistant Staphylococcus aureus in a tertiary care hospital. Australas Med J. 2013;6(10):496-503.
22. Blanc DS, Lugeon C, Wenger A, Siegrist HH, Francioli P. Quantitative antibiogram typing using inhibition zone diameters compared with ribotyping for epidemiological typing of methicillin-resistant Staphylococcus aureus. J Clin Microbiol. 1994;32(10):2505-9.

23. Matuschek E, Brown DF, Kahlmeter G. Development of the EUCAST disk diffusion antimicrobial susceptibility testing method and its implementation in routine microbiology laboratories. Clin Microbiol Infect. 2014;20(4):255-66.

24. Vainio A. Molecular methods for the epidemiological analysis of methicillin-resistant Staphylococcus aureus (MRSA) and Streptococcus pneumoniae. Finlad, Tampere: National Institute for Health and Welfare (THL). 2012:p.35-45.

25. Fitzgerald JR, Meaney WJ, Hartigan PJ, Smyth CJ, Kapur V. Finestructure molecular epidemiological analysis of Staphylococcus aureus recovered from cows. Epidemiol Infect. 1997;119(2):261-9.

26. Combe ML, Lemeland JF, Pestel-Caron M, Pons JL. Multilocus enzyme analysis in aerobic and anaerobic bacteria using gel electrophoresis-nitrocellulose blotting. FEMS Microbiol Lett. 2000;185(2):169-74.

27. Kosikowska U, Stepien-Pysniak D, Pietras-Ozga D, Andrzejczuk S, Juda M, Malm A. Application of MALDI-TOF MS for identification of clinical isolates of bacteria from humans and animals [In Polish]. Diagn Lab. 2015;51(1):23-30.

28. Manukumar HM, Umesha S. MALDI-TOF-MS based identification and molecular characterization of food associated methicillinresistant Staphylococcus aureus. Sci Rep. 2017;7(1):1-16.

29. Gagnaire J, Dauwalder O, Boisset $S$, Khau D, Freydière AM, Ader F et al. Detection of Staphylococcus aureus delta-toxin production by whole-cell MALDI-TOF mass spectrometry. PloS One. 2012;7(7):e40660.

30. Dubois D, Leyssene D, Chacornac JP, Kostrzewa M, Schmit PO, Bonnet $\mathrm{R}$ et al. Identification of a variety of Staphylococcus species by matrix-assisted laser desorption ionization-time of flight mass spectrometry. J Clin Microbiol. 2010;48(3):941-5.

31. Szabados F, Woloszyn J, Richter C, Kaase M, Gatermann S. Identification of molecularly defined Staphylococcus aureus strains using matrix-assisted laser desorption/ionization time of flight mass spectrometry and the Biotyper 2.0 database. J Med Microbiol. 2010;59(7):787-90.

32. Josten M, Reif M, Szekat C, Al-Sabti N, Roemer T, Sparbier K, et al. Analysis of the MALDI-TOF mass spectrum of Staphylococcus aureus identifies mutations which allow differentiation of the main clonal lineages. J Clin Microbiol. 2013:JCM-00518.

33. Spinali S, Van Belkum A, Goering RV, Girard V, Welker M, Van Nuenen M, et al. Microbial typing by matrix-assisted laser desorption ionization-time of flight mass spectrometry: do we need guidance for data interpretation? J Clin Microbiol. 2015;53(3):760-5. 